\title{
Origin and Early Development of the Posterior Lateral Line System of Zebrafish
}

\author{
Andres F. Sarrazin, ${ }^{1 *}$ Viviana A. Nuñez,${ }^{1,2 *}$ Dora Sapède, ${ }^{1 *}$ Valériane Tassin, ${ }^{1}$ Christine Dambly-Chaudière, ${ }^{1}$ \\ and Alain Ghysen ${ }^{1}$ \\ ${ }^{1}$ Laboratory of Neurogenetics, Inserm, and Université Montpellier 2, 34095 Montpellier, France, and ²Departamento de Biología, Universidad de Chile, \\ Casilla 653, Santiago, Chile
}

The lateral line system of teleosts has recently become a model system to study patterning and morphogenesis. However, its embryonic origins are still not well understood. In zebrafish, the posterior lateral line (PLL) system is formed in two waves, one that generates the embryonic line of seven to eight neuromasts and 20 afferent neurons and a second one that generates three additional lines during larval development. The embryonic line originates from a postotic placode that produces both a migrating sensory primordium and afferent neurons. Nothing is known about the origin and innervation of the larval lines. Here we show that a "secondary" placode can be detected at $24 \mathrm{~h}$ postfertilization (hpf), shortly after the primary placode has given rise to the embryonic primordium and ganglion. The secondary placode generates two additional sensory primordia, primD and primII, as well as afferent neurons. The primary and secondary placodes require retinoic acid signaling at the same stage of late gastrulation, suggesting that they share a common origin. Neither primary nor secondary neurons show intrinsic specificity for neuromasts derived from their own placode, but the sequence of neuromast deposition ensures that neuromasts are primarily innervated by neurons derived from the cognate placode. The delayed formation of secondary afferent neurons accounts for the capability of the fish to form a new PLL ganglion after ablation of the embryonic ganglion at 24 hpf.

\section{Introduction}

The posterior lateral line (PLL) system of teleosts comprises a set of discrete mechanosensory organs (neuromasts) arranged in reproducible patterns on the body and tail, and their afferent neurons (Coombs et al., 1989). In zebrafish, the PLL system arises from a cranial placode that appears just caudal to the otic vesicle around $18 \mathrm{~h}$ postfertilization (hpf) (Kimmel et al., 1995). This placode divides into an anterior group of $\sim 20$ cells, which becomes the PLL ganglion, and a posterior group of $\sim 80$ cells, the PLL primordium (primI). At $22 \mathrm{hpf}$, primI has begun to migrate along the horizontal myoseptum toward the tip of the tail, where it arrives around $40 \mathrm{hpf}$ (Kimmel et al., 1995). Growth cones of sensory neurons accompany the migrating primordium (Metcalfe, 1985; Gilmour et al., 2004). During its journey, primI deposits five clusters of $\sim 20$ cells, each of which will form a neuromast (L1-L5), and eventually fragments to form two or three termi-

Received 0ct. 15, 2009; revised Dec. 21, 2009; accepted Jan. 11, 2010.

This work was supported by the Agence Nationale pour la Recherche, by the Association pour la Recherche sur le Cancer, and by a cooperation grant between the Comisión Nacional de Investigación Científica y Tecnológica (CONICYT, Chile) and the Comité Evaluation de la Coopération Scientifique (ECOS-Sud, France). We thank M. BronnerFraser for expert editorial assistance; R. Ladher, C. Baker, and G. Schlosser for helpful discussions about placodes; V. McCabe for comments on this manuscript; and two anonymous reviewers for their stimulating comments. N. Cubedo provided excellent fish care.

${ }^{*}$ A.F.S., V.A.N., and D.S. contributed equally to this work.

Correspondence should be addressed to Alain Ghysen, Inserm U881, cc103 UM2, place E. Bataillon, 34095

Montpellier, France. E-mail: alain.ghysen@univ-montp2.fr.

A. F. Sarrazin's present address: Institute of Molecular Biology and Biotechnology, 71110 Iraklio Crete, Greece.

D. Sapède's present address: Department of Experimental and Health Sciences, Barcelona Biomedical Research Park, c/ Dr. Aiguader 88, 08003 Barcelona, Spain.

D01:10.1523/JNEUROSCI.5137-09.2010

Copyright $\odot 2010$ the authors $\quad 0270-6474 / 10 / 308234-11 \$ 15.00 / 0$ nal neuromasts at the tip of the tail. By $48 \mathrm{hpf}$, the embryonic pattern is complete. In addition to the neuromasts, primI deposits a trail of interneuromast cells that will later proliferate and form intercalary neuromasts during larval development (Grant et al., 2005; LopezSchier and Hudspeth, 2005; Nuñez et al., 2009).

At $48 \mathrm{hpf}$, two new primordia have formed. One migrates along the horizontal myoseptum, much as primI did, and has been called primII; the other one migrates along the dorsal midline and has been called primD (for review, see Ghysen and Dambly-Chaudière, 2007). primII and primD deposit seven to eight and five neuromasts, respectively, as well as a trail of interneuromast cells that proliferate later during larval development and form two new lines of neuromasts (Nuñez et al., 2009). primII and primD are therefore at the origin of three of the four anteroposterior lines of neuromasts present in juvenile and adult zebrafish, yet their origin has never been investigated.

In this study, we show that the secondary components of the zebrafish PLL system, primII and primD, arise from a placode that can be detected at $24 \mathrm{hpf}$, just after the primary placode has given rise to the primary primordium and ganglion. This secondary placode also generates afferent neurons, which are essentially responsible for the appearance of a new PLL ganglion after ablation of the original ganglion at $24 \mathrm{hpf}$. The formation of both primary and secondary placodes depends on retinoic acid signaling during late gastrulation $(8-10 \mathrm{hpf})$. Because of this simultaneity, we propose that the entire PLL system derives from a group of PLL precursor cells that is set aside at $10 \mathrm{hpf}$ and forms two distinct placodes, each of which produces neurons and migrating primordia.

One interesting difference between primI-derived neuromasts and those formed by primD and primII is that the former 
comprise hair cells that are polarized along the anteroposterior axis, whereas the latter are polarized along the dorsoventral axis (Lopez-Schier et al., 2004). It is not known whether neurons can discriminate between primI-, primII-, and primD-derived neuromasts. We show that the neurons generated by the secondary placode can innervate all extant neuromasts after ablation of the embryonic PLL ganglion, indicating that secondary neurons have no intrinsic specificity for secondary neuromasts. Whereas ganglion cells appear not to be intrinsically specified to innervate neuromasts arising from a particular primordium, the sequence of development ensures that early versus late developing ganglion cells predominantly supply neuromasts derived from primI and from primII/D, respectively.

\section{Materials and Methods}

Fish. Wild-type zebrafish (Danio rerio) were obtained from Singapore through a local company (Antinea) and maintained in standard conditions (Westerfield, 2000). Embryos were obtained by natural spawning and raised at $28.5^{\circ} \mathrm{C}$ in tank water. Ages are expressed as hours or days postfertilization. The transgenic lines cldnb:gfp, Huc:kaede, and islet:gfp were kindly provided by D. Gilmour (European Molecular Biology Laboratory, Heidelberg, Germany) and H. Okamoto (RIKEN Brain Science Institute, Wako, Japan); the nbt:dsred line was provided by M. Van Drenth (Max Planck Institute for Developmental Biology, Tübingen, Germany) and D. Gilmour; Huc:gfp was given by J. Clarke (University College London, London, UK); and SqET20 was obtained from V. Khorz (Institute of Molecular and Cell Biology, Singapore) through M. Allende (Universidad de Chile, Santiago, Chile).

Photolabeling by conversion or uncaging. For fate-mapping experiments, Kaede photoconversion was performed as described previously (Nuñez et al., 2009) using a $0.05 \mathrm{~mm}$ pinhole positioned as a field diaphragm in the excitation path of an Axioplan microscope (Zeiss) and a $20 \times$ water-immersion objective, achieving an actual diameter of illumination of $25 \mu \mathrm{m}$. For fate mapping at $17.5 \mathrm{hpf}$, we used a pinhole of 0.16 $\mathrm{mm}$ and an eyepiece reticle with a square lattice to position the beam relative to the outline of the otic vesicle. For synapse conversion, we also used a $0.16 \mathrm{~mm}$ pinhole and delivered two pulses of $30 \mathrm{~s}$ each, separated by $5 \mathrm{~min}$. Two hours later, we looked for red cells in the ganglion region and recorded their positions. Manipulations were done under orange light, and embryos were protected from light at all other times. When conversion was achieved under Nomarski optics, we also used an orange filter on the light path. Efficient conversion is easily visualized by a decrease in green fluorescence (we generally avoided looking at red fluorescence before the final analysis). The results of all experiments were documented with an Axioimager microscope (Zeiss) equipped with a CoolSnap camera. Fluorescence uncaging was performed as described previously (Sapède et al., 2002; Grant et al., 2005).

4-(Diethylamino) benzaldehyde treatment. 4-(Diethylamino) benzaldehyde (DEAB; Sigma-Aldrich) was used at $50 \mu \mathrm{M}$ (Kopinke et al., 2006) by dilution of a stock solution ( $50 \mathrm{~mm}$ in DMSO). Twelve fertilized eggs were placed in $6 \mathrm{ml}$ of this solution at time $t$, transferred to $40 \mathrm{ml}$ of system water at time $t+2 \mathrm{~h}$, and transferred a second time 15 min later. At $24 \mathrm{hpf}$, the eggs to be used for counting the neurons were dechorionated and transferred to $4 \%$ paraformaldehyde in PBS at $4^{\circ} \mathrm{C}$. The eggs to be used for the assessment of otolith size and neuromast numbers were transferred to $0.001 \%$ PTU (1-phenyl-2-thiourea; Sigma) in tank water, to prevent pigmentation (adapted from Westerfield, 2000), and left to develop until 4 days postfertilization (dpf).

Quantification of otolith size and of neuromast and neuronal numbers. To quantify the abnormality of inner ear development, we measured and combined the dorsoventral diameters of the two otoliths in fixed embryos (4\% paraformaldehyde in PBS, $3 \mathrm{~h}$ at room temperature). This method to evaluate otolith size is very simple and relatively crude, but the values measured in wild-type larvae are reasonably constant. Larvae were then processed for alkaline phosphatase labeling (Villablanca et al., 2006). Whether lateral neuromasts belong to the I or II system can be unequivocally decided based both on their intrinsic polarity and on their rela- tionship to the trail of interneuromast cells deposited by primI. The neurons in the PLL ganglion were counted in the nbt:dsred line. Z-stacks (step, $1 \mu \mathrm{m}$ ) were made with a motorized FXA Microphot (Nikon) equipped with a Pentamax cooled camera driven by IPLab software. Individual neurons were traced in the various planes, to allow a complete and unambiguous neuronal count.

Ganglion ablation and time-lapse analysis. For ablation experiments, we used a Micropoint system mounted on an Axioplan microscope (Zeiss) equipped with a long-distance, water-immersion $63 \times$ objective. Embryos were anesthetized with $0.0007 \%$ benzocaine and mounted in $1 \%$ agar and $1 \mathrm{~mm} \mathrm{NaCl}$ in tank water. The laser beam was focused on each nucleus within the ganglion, and a short train of pulses was applied. The earliest effect of irradiation is visible within a few seconds, and marked changes in nuclear morphology appear within a few minutes. For time-lapse analysis, embryos were kept in agar after ganglion ablation, under anesthesis, and were inspected every hour until fluorescence could be detected in the postotic region. $Z$-stacks of five planes $5 \mu \mathrm{m}$ apart were taken every $15 \mathrm{~min}$, and a maximum intensity projection was derived from each stack.

Labeling of afferent and efferent terminals. Mass labeling of neuromast innervation was achieved by anti-acetylated tubulin immunolabeling. After fixation in 4\% paraformaldehyde in PBS, embryos were washed two times for $5 \mathrm{~min}$ in PBS, washed two times for $5 \mathrm{~min}$ in water, treated 7 min with aceton at $-20^{\circ} \mathrm{C}$, washed $5 \mathrm{~min}$ in water, washed 5-10 $\mathrm{min}$ in PBS with $1 \%$ Tween 20 and $0.5 \%$ Triton X-100 (PBTT), treated with blocking solution (PBT with $1 \%$ BSA and $1 \%$ DMSO) for $2 \mathrm{~h}$, incubated overnight at $4^{\circ} \mathrm{C}$ with primary antibodies diluted in blocking solution [1:400 anti-acetylated tubulin (Sigma) and 1:200 anti-green fluorescent protein (GFP; Clontech)], washed five times for $20 \mathrm{~min}$ in PBTT, incubated overnight at $4{ }^{\circ} \mathrm{C}$ with the secondary antibodies conjugated to Alexa Fluor-568 (red) and Alexa Fluor-488 (green) (both from Invitrogen and diluted 1:400 in blocking solution), washed five times for $20 \mathrm{~min}$ in PBTT, and washed three times for $10 \mathrm{~min}$ in PBS. All washes were done at room temperature. Embryos were kept in 1:1 glycerol-PBS and observed with a fluorescence microscope (Leica DM6000B). Pictures were assembled from $z$-stacks (step, $2 \mu \mathrm{m}$ ).

Neurons innervating individual neuromasts were labeled by iontophoretic application of DiI, using a WPI 767 electrometer, to neuromasts visualized on a fixed-stage Axioscop microscope (Zeiss) equipped with a long-distance, water-immersion $63 \times$ objective and Nomarski optics. In the case of injections done in islet:gfp embryos, where the efferent axons contain GFP, confocal images were taken on a TCS SPE laser-scanning confocal microscope (Leica) equipped with a long-distance, waterimmersion $40 \times$ objective. Images used for the figures are maximum projections from four to six consecutive frames; the $z$-step was $1 \mu \mathrm{m}$. Because the fluorescence of DiI is much stronger than that of GFP in this experiment, DiI fluorescence leaks into the GFP channel. To reduce this overlap, GFP fluorescence was excited with a $488 \mathrm{~nm}$ laser at $100 \%$ full intensity, and emission was restricted to $495-525 \mathrm{~nm}$ (i.e., $15 \mathrm{~nm}$ on either side of the peak of GFP emission). DiI fluorescence was elicited with a $532 \mathrm{~nm}$ laser at $20 \%$ full intensity, and emission was recorded between 570 and $630 \mathrm{~nm}$. Dichroic mirrors were replaced by a $30 \%$ reflection $/ 70 \%$ transmission mirror. Under these conditions, contamination of GFP by DiI fluorescence was much reduced.

\section{Results}

\section{Fate map of the PLL placode}

The cranial placodes of vertebrates can usually be detected as ectodermal thickenings, but this is not the case in zebrafish. Molecular markers such as eyal and six 1 expression reveal the existence of a horseshoe-shaped region surrounding the anterior neural plate around the tailbud stage $(10 \mathrm{hpf})$. This region is supposed to define a preplacodal domain that is later subdivided into distinct placodes (for review, see Baker and Bronner-Fraser, 2001; Schlosser, 2006). The expression of both eyal and sixl is later confined to some placodes, including lateral line placodes (Sahly et al., 1999; Bessarab et al., 2004; Schlosser, 2006). 
To visualize the PLL placode in living embryos, we used the cldnb:gfp line (Haas and Gilmour, 2006). In this line, GFP is present in all derivatives of the placode (migrating primordia and ganglion), suggesting that there might also be expression in the placode itself. GFP expression can first be detected at $17 \mathrm{hpf}$ (16-somite stage) and soon extends to a large group of cells between the posterior edge of the otic vesicle and the anterior boundary of the first somite (Fig. 1A, $17.5 \mathrm{hpf}, 17$-somite stage). This group of cells is located just below the periderm cells (Fig. $1 B$ ), and its shape resembles that of eyal expression at the same stage (Fig. 1C), supporting the idea that these cells belong to the PLL placode. We determined the organization of this putative placode by using the photoconvertible fluorescent protein Kaede (Ando et al., 2002). Briefly, we injected Kaede mRNA at the one-cell stage, let the embryo develop until the desired stage, and converted the protein from green to red fluorescence in small regions by illuminating with a thin beam of UV light. We used as a reference landmark the otic primordium, which can be detected under Nomarski optics starting at $\sim 14 \mathrm{hpf}$ (Kimmel et al., 1995). We performed the photoconversions at $17.5 \mathrm{hpf}, 3 \mathrm{~h}$ before PLL placode derivatives can first be detected under Nomarski optics.

We photoconverted cells at eight different positions within the putative placodal domain, and we tracked the fate of the irradiated cells at 24, 30, 48, and $72 \mathrm{hpf}$, looking for red cells in the ganglion, primordia, neuromasts, and interneuromast cells. One example is shown in Figure 1, $D$ and $E$, illustrating photoconversion just anterior to the first somite $(D)$ and the presence of converted Kaede in primI $(E)$. The results are shown Figure $1 F$, where horizontal stripes indicate that converted cells were later found in the ganglion and vertical stripes indicate the presence of converted cells in primI and/or in primI-derived neuromast and interneuromast cells. Both cases in which neurons were marked correspond to irradiations in the rostral region of the placodal field, suggesting that the rostral one-fourth (approximately) of the field may preferentially or exclusively form neurons, whereas the caudal three-fourths would exclusively produce primordium cells. The two cases in which irradiation was targeted on the first somite did not yield converted cells in the PLL system, supporting the conclusion that the placode that forms the embryonic system extends between the otic placode and the first somite.

Photoconversion in the putative placodal region at $17.5 \mathrm{hpf}$ resulted in labeling of all embryonic PLL derivatives (primI or PLL ganglion), but we did not observe labeling in the primII or primD system. To see whether the latter originates from another region, we photoconverted the entire head, anterior to somite 1 , in four embryos. Conversion was done between 15 and $17 \mathrm{hpf}$, and the embryos were examined at $48 \mathrm{hpf}$. In all cases, we observed extensive labeling of all primI-derived neuromasts, but either no labeling at all in primII (two cases) or very weak labeling of a few (one to three) cells, indicating that this method cannot be used to reliably localize the origin of primII/primD.

\section{Origin of the primII/primD system}

The group of cells from which primII and primD are derived can first be seen with Nomarski optics around $34 \mathrm{hpf}$ and was named D0 (Sapède et al., 2002). D0 is located at the anterior boundary of somite 1 and remains there for several hours before splitting into primII and primD (Fig. 2A). Labeling D0 cells by fluorescein uncaging experiments confirmed that they end up in primII and primD (Sapède et al., 2002). In some $34 \mathrm{hpf}$ embryos, the D0 cluster was not present on somite 1 , and in those cases, clusters of cells similar to D0 could be seen at intermediate positions between somite 1 and the ganglion. This led us to try uncaging the region of the ganglion around $24 \mathrm{hpf}$, shortly after primI has begun its migration. Anti-fluorescein labeling was performed at $50 \mathrm{hpf}$. We observed in all cases that primD and primII were labeled (Fig. 2B).

We wondered whether the ganglion itself might be at the origin of primII and primD. To answer this question, we examined ngn1-MO larvae, where the ganglion does not form (Andermann et al., 2002). We scored the PLL system at $4 \mathrm{dpf}$, a time when primII and primD have formed two neuromasts each. At this age, ngn1-MO embryos begin to develop supernumerary neuromasts (Grant et al., 2005), but these are easily distinguished from primII and primD neuromasts based on their size and connection with the interneuromast cells. We observed that primII- and primD-derived neuromasts are present in the morphant embryos 


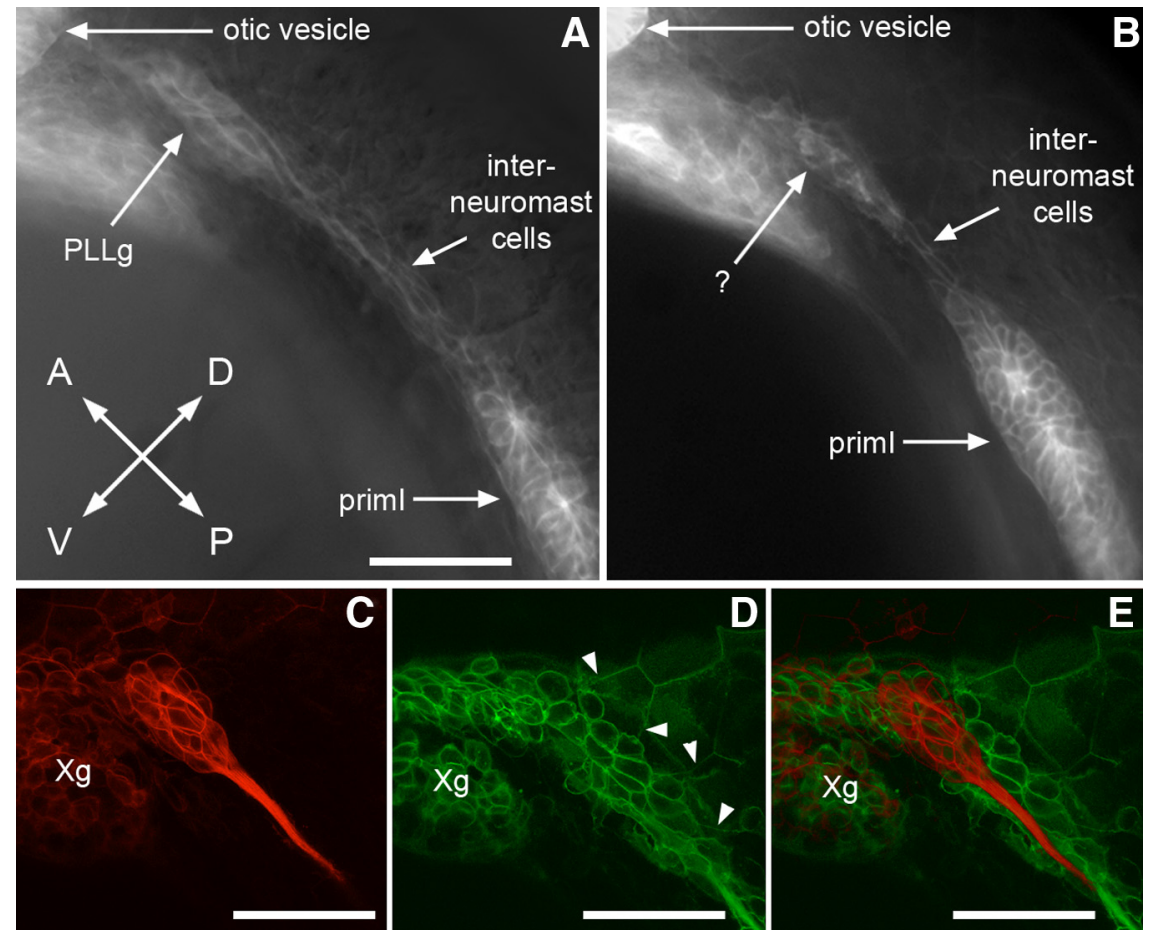

Figure 3. Detection of the secondary placode in cldnb-gfp embryos. $A$, Control cldnb:gfp embryo at $24 \mathrm{hpf}$ showing fluorescence in the otic vesicle, PLL ganglion (PLLg), interneuromast cells, and priml. $\boldsymbol{B}$, ngn 1-M0-injected cldnb:gfp embryo lacks a PLL ganglion, but a group of GFP-positive cells is present at a similar position (question mark). Note that priml is slightly delayed relative to the untreated embryo; such a delay is often observed after injecting eggs. ( $-\boldsymbol{E}$, Two different focal planes of a confocal stack taken in a cldnb:gfp embryo at $24 \mathrm{hpf}$. The deeper plane (C) runs through the PLL ganglion, and the more superficial plane (D) runs through the putative secondary placode. The deep plane has been falsely colored in red to allow superposition with the superficial plane $(\boldsymbol{E})$, illustrating the almost complete overlap between the PLL ganglion and the secondary placode. Note that the border of peridermal cells (arrowheads) abut the placodal cells in $\boldsymbol{D}$, implying that the placodal cells are located right under the basal membrane of the periderm. Xg, Vagal ganglion. In all panels, anterior is top left and dorsal is top right. Scale bars: $50 \mu \mathrm{m}$.

in normal numbers and at normal positions (data not shown). This result indicates that the ganglion is not at the origin of the primD/II system and that other cells in the postotic region must be involved. We looked directly for such cells using the cldnb:gfp line. The rationale was that $c l d n: g f p$ is expressed in the primI placode several hours before migration begins and may be similarly expressed in the primD/II progenitor cells.

We first examined the postotic region in ngn1-MO,cldn:gfp embryos to avoid the massive fluorescence caused by the ganglion cells. At $24 \mathrm{hpf}$, when primI has left the presomitic domain, we observed a cluster of fluorescent cells in the region between the otic vesicle and the first somite (Fig. $3 B$, question mark). This cluster is attached to the line of interneuromast cells deposited by primI, and it mostly overlaps the location where the ganglion would have been (Fig. 3, compare $A, B$ ). We then examined whether these cells could be detected by confocal microscopy in untreated cldn:gfp embryos. We observed a group of $\sim 70$ fluorescent cells at the level of the ganglion, but in a more superficial position, just under the periderm (Fig. 3C-E). This corresponds exactly to the position of the cluster observed in ngn 1-MO embryos (Fig. 3B). It must be noted, however, that the number of cells observed in this region in ngn1-MO embryos appears smaller than the number of cells in untreated embryos, possibly related to the absence of neural progenitors in the morphant embryos.

To see whether the subperidermal cldnb:gfp cells are indeed at the origin of the primII/primD system, we performed Kaede photoconversions aimed at these cells in $n g n 1$ morphant embryos.
We performed the photoconversion at $20.5 \mathrm{hpf}$, when primI prepares to migrate. In a very small proportion of the embryos, GFP-positive primI cells can be detected despite the general Kaede fluorescence, and the region between primI and the otic vesicle can be targeted (Fig. $4 A$ ). Of four successful conversions, we observed red cells in D0 in all cases at $35 \mathrm{hpf}$ (Fig. 4B). We later observed converted cells in primII in all cases (Fig. 4C), also in primD in one case, and in D1 in the other three cases (Fig. 4C; $A-C$ correspond to the same embryo).

Having established that primII/primD progenitor cells are present just under the postotic periderm in MO-ngnl embryos at $20.5 \mathrm{hpf}$, we performed similar photoconversions in untreated cldn:gfp embryos. We observed labeling in all secondary primordia between 48 and 54 hpf, much like the case of the MO-ngn1 embryos (primII, six of eight; primD, four of eight; D1, eight of eight; data not shown). This result confirms that the D/II system originates from subperidermal cells present just posterior to the otic vesicle at $20.5 \mathrm{hpf}$.

\section{Origin of the neurons that innervate} primII- and primD-derived neuromasts Nothing is known about the sensory neurons that innervate primII- and primDderived neuromasts, and, in particular, it has not been described whether they are interspersed with the neurons of the primI system or whether they are segregated as an independent ganglion. We determined the positions of the sensory neurons that innervate neuromasts of the primI, and of the primII/D, system by photoconverting neuromasts of either system in $4 \mathrm{dpf} H u c$ :kaede transgenic larvae (Sato et al., 2006). In this line, Kaede protein is present in all PLL neurons, including in their synaptic endings, and can be converted in any chosen neuromast (Fig. 4D). This conversion leads after 1-2 $\mathrm{h}$ to labeling of neuron somata, because of diffusion of the converted Kaede from the synaptic terminals (Fig. $4 E$ ).

UV irradiation of six L1 neuromasts (the anteriormost of the primI-derived neuromasts) or of five LII.1 neuromasts (the anteriormost of the primII-derived neuromasts) resulted, in all cases, in the presence of red neurons within the PLL ganglion. We observed, however, that the distribution of the two types of neurons is not random: $81 \%$ ( 17 of 21 ) of the $\mathrm{L} 1$ neurons had their bodies in the dorsal half of the ganglion, whereas only $43 \%$ ( 6 of 14) of the LII.1 neurons were found in this half (Fig. $4 F$ ). Thus, although the primI and primII/D neurons are interspersed within the same ganglion, there is clearly a preferential distribution of somata within the ganglion. That the segregation is only partial may be related to the fact that some neurons innervate both LI and LII neuromasts (see below).

\section{Organization of the II/D placode}

Given the similarity between the placode observed at $17.5 \mathrm{hpf}$ in the $c l d n b: g f p$ line, which forms primI and its afferent neurons 

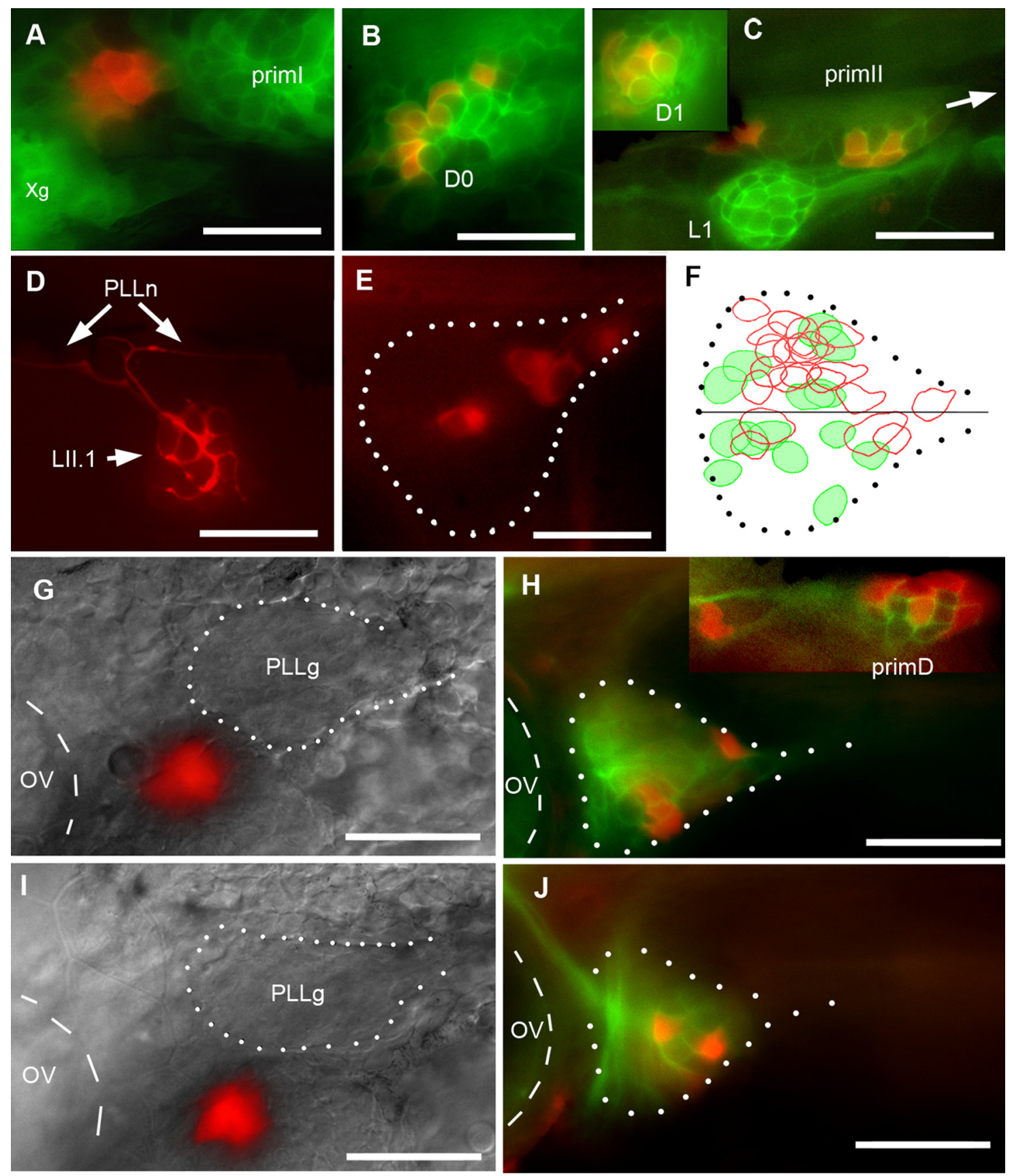

Figure 4. Origin of secondary primordia and neurons. $A-C$, cldnb:gfp embryo coinjected with Kaede mRNA and ngn 1 -MO was photoconverted at $20.5 \mathrm{hpf}(\boldsymbol{A})$, when priml begins to migrate, and examined at $35 \mathrm{hpf}(\boldsymbol{B})$ and $54 \mathrm{hpf}(\boldsymbol{C})$. In C, primll is migrating along L1 (arrow indicates direction of migration). The inset shows D1 at the same stage. Xg, Vagal ganglion. $\boldsymbol{D}$, Synaptic endings in neuromast Lll.1 of a $4 \mathrm{dpf}$ Huc:kaede larva, a few minutes after photoconversion. PLLn, PLL nerve. $\boldsymbol{E}$, Two hours after conversion, four neurons are labeled in the ganglion (dotted outline). $\boldsymbol{F}$, The neurons innervating L1 ( $n=6$; red circles) and LII.1 ( $n=5$; green) are intermingled in the same ganglion (dotted outline), although there is partial segregation along the dorsoventral direction, with neurons innervating L1 (red) located preferentially in the dorsal half of the ganglion. G-J, Photoconversion of subperidermal cells anterior and ventral to the PLL ganglion in $24 \mathrm{hpf}$ cldnb-GFP embryos injected with Kaede mRNA at the one-cell stage, avoiding the ganglion (PLLg), results in the presence of converted neurons in the ganglion at $48 \mathrm{hpf}(\boldsymbol{H}, \boldsymbol{J}) . \mathbf{G}, \boldsymbol{I}, \mathbf{M e r g e d}$ Nomarski and red fluorescence images. $\boldsymbol{H}, \boldsymbol{J}$, Merged green (cldnb-gfp plus unconverted Kaede expression) and red fluorescence. Inset, Converted cells in primD (dorsal is to the right). In all panels, anterior is to the left, and dorsal up. The otic vesicle is outlined with dashed lines, and the PLL ganglion is outlined with white dots. Scale bars, $50 \mu \mathrm{m}$. PLLg, PLL ganglion; OV, otic vesicle.

(Fig. 1C), and the group of subperidermal cells observed at $24 \mathrm{hpf}$ in the postotic region (Fig. $3 B, D$ ), we thought that the two territories might be similarly organized, with a presumptive neural region anteriorly and a presumptive primordium region posteriorly. Subperidermal GFP-positive cells can be detected in $24 \mathrm{hpf}$ cldn:gfp embryos without resorting to confocal microscopy, as long as they are not directly above the ganglion. We performed photoconversions around the PLL ganglion, mostly in more an- terior and ventral positions, a region where putative placodal cells extend some distance from the ganglion (Fig. 3E).

We photoconverted groups of $\sim 10$ cells in $1224 \mathrm{hpf}$ embryos and examined the ganglion $1 \mathrm{~d}$ later. We found converted neurons in six cases in which we converted cells anterior and ventral to the PLL ganglion (Fig. $4 G-J$ ). In another four cases, we did not find labeled neurons. In two cases in which we converted subperidermal cells dorsal to the ganglion, we also failed to see converted 


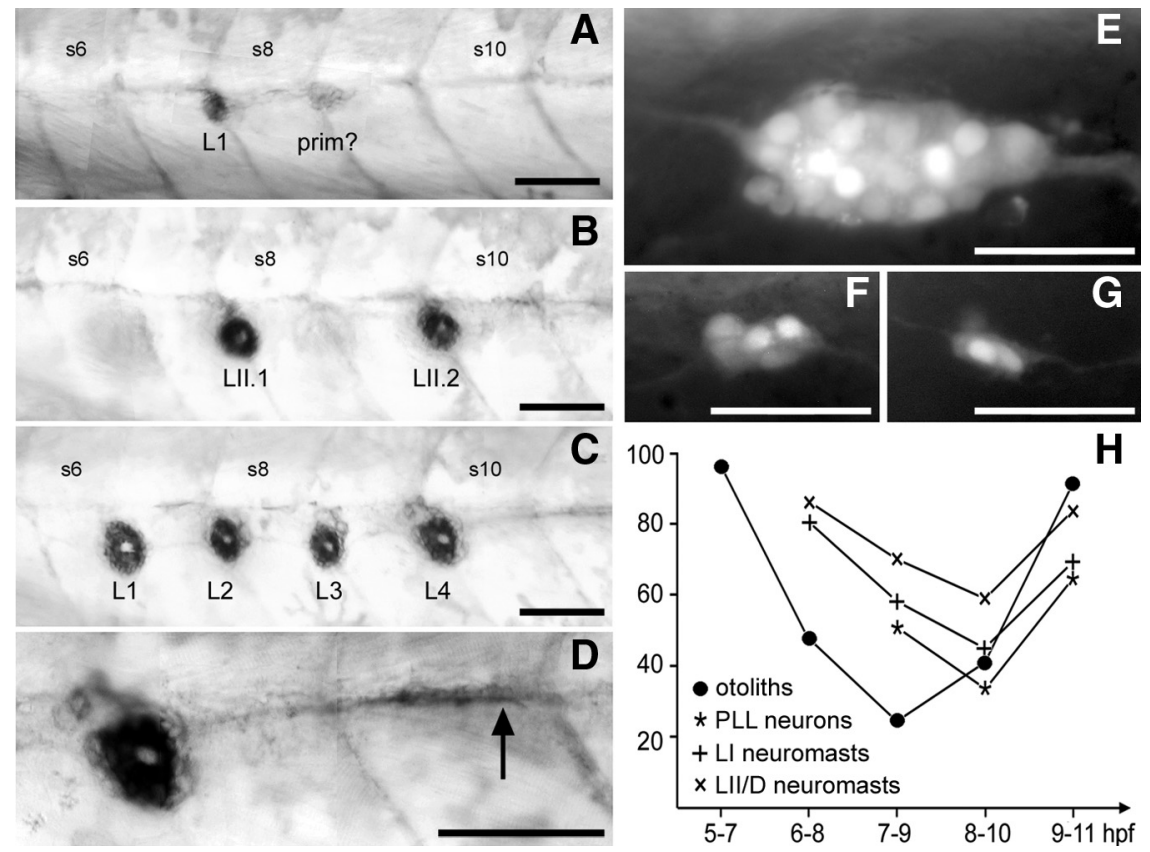

Figure 5. Effect of DEAB treatment on the PLL. $A$, An extreme case in which only one neuromast, L1, has formed at $4 \mathrm{dpf}$. Posterior to $L 1$ is an immobilized primordium (prim?); it is not possible to decide whether this corresponds to priml or primll. $B, A$ case in which LI neuromasts, but not LII, are completely absent. LI and LII neuromasts can be distinguished based on the central, unlabeled region that is oriented along the anteroposterior axis in LI neuromasts and along the dorsoventral axis in LII (Nuñez et al. 2009). C, A case in which LII neuromasts, but not $L$, are absent. $\boldsymbol{D}$, Higher magnification of the array shown in $\boldsymbol{C}$, to illustrate the arrest of interneuromast cells shortly after the last deposited neuromast (arrow). $\boldsymbol{E}$, Normal pattern of neurons in a 28-30 hpf nbt:dsred embry0, with $21 \pm 2$ neurons decorated by the fluorescent marker DsRed. $\boldsymbol{F}, \boldsymbol{G}$, Reduced ganglia after DEAB treatment. $\boldsymbol{H}$, Time course of the DEAB effect. For each period of treatment (abscissa), the experimental data of Table 1 are expressed as percentage of the control. + , LI neuromasts; $\times$, LII/D neuromasts; ${ }^{*}$, neurons; O, otoliths. Scale bars, $50 \mu \mathrm{m}$. S6, S8, and S10, Somite numbers.

Table 1. Effect of DEAB treatments at different times on otolith size, number of neuromasts of the primary and secondary systems, and number of neurons in the PLL ganglion

\begin{tabular}{lllllll}
\hline$t$ (hpf) & Otoliths & NMI & NMII/D & N1 & Neurons & N2 \\
\hline $5-7$ & $3.8 \pm 0.3$ & nd & nd & 10 & nd & \\
$6-8$ & $1.9 \pm 0.8$ & $7.3 \pm 1.2$ & $3.8 \pm 0.8$ & 45 & nd & \\
$7-9$ & $1.0 \pm 0.5$ & $5.2 \pm 1.7$ & $3.1 \pm 0.7$ & 41 & $10.1 \pm 1.9$ & 14 \\
$8-10$ & $1.6 \pm 1.1$ & $4.1 \pm 1.9$ & $2.6 \pm 0.9$ & 40 & $6.6 \pm 2.4$ & 24 \\
$9-11$ & $3.7 \pm 0.4$ & $6.3 \pm 1.3$ & $3.7 \pm 0.8$ & 30 & $12.9 \pm 1.5$ & 12 \\
ctrl & 4.0 & $9.1 \pm 0.7$ & $4.4 \pm 0.5$ & 20 & $19.8 \pm 2.2$ & 12 \\
\hline
\end{tabular}

$\mathrm{N} 1$, Number of samples for the first three columns, examined at $4 \mathrm{dpf}$; $\mathrm{N} 2$, number of samples for the neuronal counts, examined at $24 \mathrm{hpf}$. The cumulated size of otoliths was measured as the sum of the heights of the otoliths present, and the number and type of neuromasts were determined after alkaline phosphatase labeling (see Materials and Methods).

neurons. We conclude that cells present in the postotic region at 24 hpf generate neurons that will end up within the PLL ganglion 1 d later.

In one case, we observed photoconverted cells not only in the ganglion, but also in primD (Fig. $4 H$, inset), suggesting that the presumptive territories for neurons and for migrating primordia are adjacent within the secondary placode, similar to what we observed in the primary placode.

\section{Origin of the primary and secondary placodes}

It is currently believed that the PLL and inner ear are derived from a common posterior placode [together with epibranchial ganglia (for review, see Schlosser, 2006; Baker et al., 2008)]. To decide whether the primary and secondary PLL placodes are initially established as a single group of PLL precursor cells, or as two independent entities, we tried to interfere with the formation of the system. Fortuitous observations suggested that this could be achieved by interfering with retinoic acid signaling.

Retinoic acid is an essential component for the proper patterning of the anterior region of the vertebrate embryo in neurectoderm (Durston et al., 1989), in mesoderm (Ruiz i Altaba and Jessell, 1991), and in endoderm (Stafford and Prince, 2002). DEAB is an inhibitor of retinaldehyde, the enzyme that synthetizes retinoic acid, and can be used to deplete retinoic acid during embryogenesis (Kopinke et al., 2006). We observed that treating embryos with DEAB between 4 and $10 \mathrm{hpf}$ leads to dramatic defects in the formation of the PLL system and of the inner ear.

In the PLL system, DEAB treatment results in a reduction in neuromast number and also in a reduction in the PLL ganglion. These effects can be quantitatively assessed by counting the number of neuromasts and ganglion cells, as described in Materials and Methods. The inner ear is also reduced in size and altered in its organization, but the complicated shape of this organ makes the abnormalities difficult to quantify. We noticed, however, a reduction in otolith size affecting the posterior otolith first and, in the most severe cases, the anterior otolith as well. Thus, we used the combined otolith size as a measure of inner ear normality (see Materials and Methods).

To better define the phenocritical period, we examined whether the time window of exposure to DEAB could be narrowed down from 6 to 3, 2, or $1 \mathrm{~h}$. We observed that $1 \mathrm{~h}$ treatments had essentially no effect on inner ear or PLL development but that $2 \mathrm{~h}$ treatments resulted in clear defects, including reduction in neuromast number both in the primI and in the primII/D systems (Fig. 5A-D), decrease in the size of the PLL ganglion (Fig. $5 E-G)$, and reduction in otolith size and number.

We assessed the phenocritical periods for these various defects by treating embryos for $2 \mathrm{~h}$ periods shifted $1 \mathrm{~h}$ apart (i.e., 5-7, $6-8,7-9$ hpf, etc.). The results are shown Table 1 and Figure $5 H$. It appears that the requirement for retinoic acid is temporally distinct for the development of the PLL and of the inner ear (as quantified by the size of otoliths). On the contrary, the time course of this requirement is closely superimposed for the primI neuromasts, the primII/D neuromasts, and the ganglion. One explanation for the identical phenocritical periods could be that the secondary placode is induced by the primary placode, or that both systems depend on a common inducing territory (possibly in the hindbrain, endoderm, or mesoderm) that would itself depend on retinoic acid signaling between 8 and 10 hpf. In either case, the primI and primII phenotypes should be closely correlated, reflecting the intensity of defect in the retinoic acid target tissue. The correlation coefficient between the numbers of LI and LII/D neuromasts, for embryos treated with DEAB between 8 and $10 \mathrm{hpf}$, is only 0.057 for 40 cases, making this explanation unlikely.

If both primary and secondary systems derive from a common pool of precursor cells, strong reductions in the size of this group 

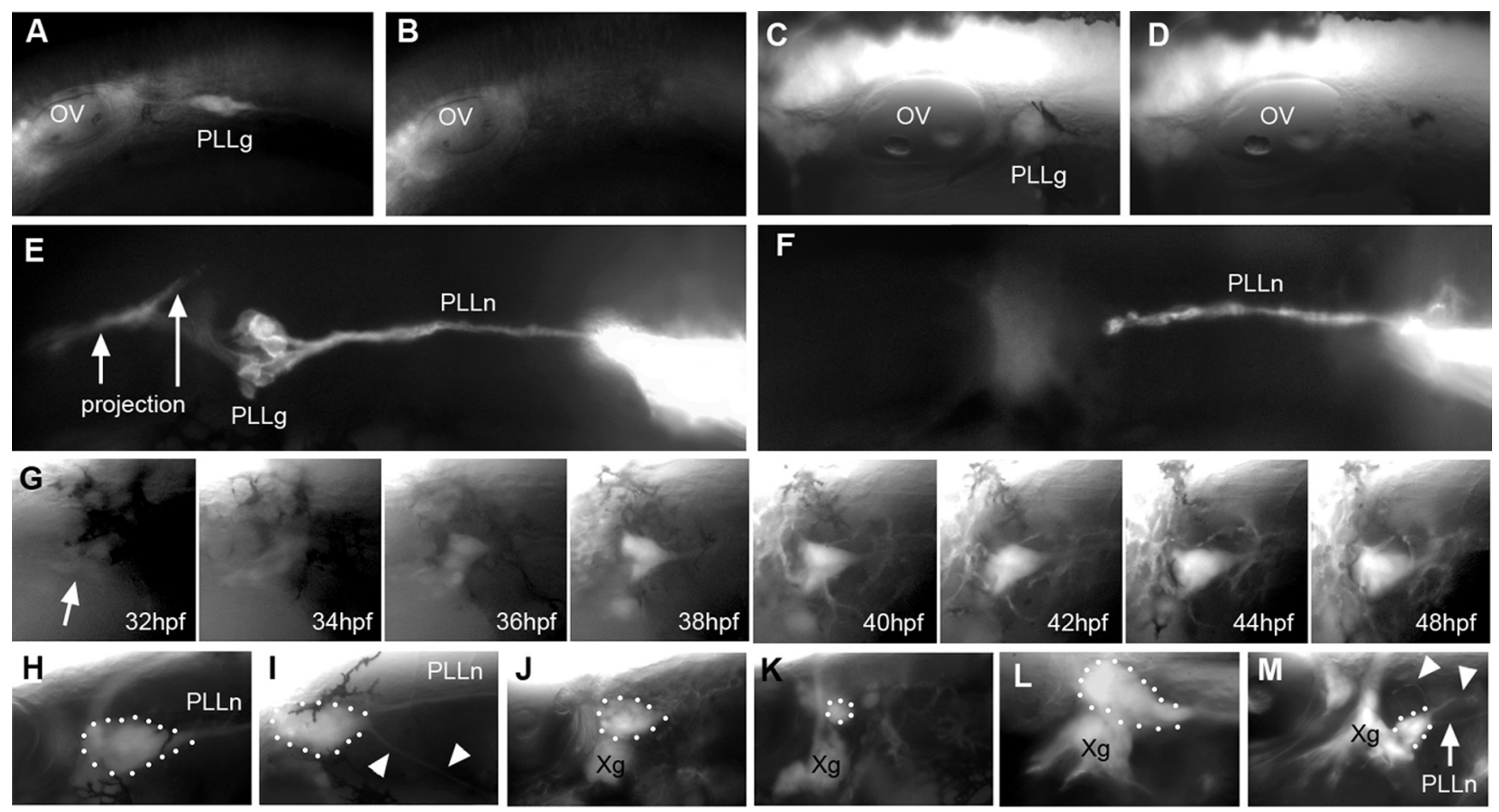

Figure 6. Regeneration of the PLL ganglion. $\boldsymbol{A}, \boldsymbol{B}, \mathrm{PLL}$ ganglion at $24 \mathrm{hpf}$ just before ablation $(\boldsymbol{A})$ and $2 \mathrm{~h}$ later $(\boldsymbol{B}) . \boldsymbol{C}, \boldsymbol{D}, \mathrm{PLL}$ ganglion at $48 \mathrm{hpf}$ just before $(\boldsymbol{C})$ and $2 \mathrm{~h}$ after ablation $(\boldsymbol{D})$. $\boldsymbol{E}, \boldsymbol{I}, \mathrm{Di}$ labeling of the PLL nerve in a control embryo $(\boldsymbol{E})$ and $2 \mathrm{~h}$ after ablation of the ganglion at $36 \mathrm{hpf}$. The PLL projection in the hindbrain is arrowed. $\boldsymbol{G}$, After ablation at $24 \mathrm{hpf}$, a successive view of the regenerating ganglion at different times. Panels from 34 to $44 \mathrm{hpf}$ are frames from a time-lapse movie taken at one $z$-stack every $15 \mathrm{~min}$. The arrow points to the first sign of fluorescence in the region of the ablated ganglion. $\boldsymbol{H}-\boldsymbol{M}$, Regenerated ganglia $1 \mathrm{~d}$ after ablation at $24 \mathrm{hpf}(\boldsymbol{H}, \boldsymbol{I})$, at $36 \mathrm{hpf}(\boldsymbol{J})$, at $38 \mathrm{hpf}(\boldsymbol{K})$, and at $40 \mathrm{hpf}(\boldsymbol{M} ; \boldsymbol{L}$ is the control side of the same embryo). Arrowheads in $\boldsymbol{I}$ and $M$ indicate ectopic nerves arising from the regenerated ganglion. Anterior is to the left in all panels except $L$, which has been inverted along the horizontal axis to facilitate comparison. $0 \mathrm{~V}, 0$ tic vesicle; PLL, PLL ganglion; PLLn, pLL nerve; Xg, vagal ganglion.

would cause a decrease in both the LI and LII/D systems, leading to size correlation. Fluctuations in the partitioning of this reduced group of cells would favor one system at the expense of the other, however, leading to an inverse correlation between the size of the two systems. These two effects might roughly cancel each other, leading to the observed lack of correlation. In support of this interpretation, we observed cases in which both LI and LII/D neuromasts were strongly reduced in numbers (Fig. 5A), but also cases in which either the LI (Fig. 5B) or the LII (Fig. 5C,D) system was much more affected than the other. Note in Figure 5, $C$ and $D$, the close packing of the LI neuromasts and arrest of interneuromast cells two somites posterior to the last neuromast (arrow), two features that are often observed after ablations removing more than two-thirds of the primordium (A. Ghysen, unpublished observations).

\section{Regeneration of the PLL ganglion}

After complete ablation or extirpation of the PLL ganglion at 24 hpf, a new ganglion has formed and regenerated a new nerve, at 48 hpf (Grant et al., 2005; our unpublished observations). Could this process involve the late development of neurons from the secondary placode? We first evaluated the efficiency of lasermediated ganglion ablation in the Huc:gfp strain, where all neurons are fluorescent. No neuron could be detected after $2 \mathrm{~h}$ when ablation was performed at either $24 \mathrm{hpf}$ (Fig. 6A,B) or at $48 \mathrm{hpf}$ (Fig. 6C,D). We confirmed the loss of neurons by labeling the nerve through DiI injection in PLL neuromasts, $2 \mathrm{~h}$ after ablation (Fig. 6, F). The axons can still be labeled, but no cell body can be detected anymore.

We then examined the dynamics of regeneration by using time-lapse analysis (Fig. 6G). For ablations performed at $24 \mathrm{hpf}$, the first signs of fluorescence were seen at $32 \mathrm{hpf}$. Grant et al. (2005) also reported that after manual extirpation of the PLL ganglion, the first newly formed axons can be detected around 33 hpf. The number of neurons and intensity of fluorescence increased progressively between 32 and $42 \mathrm{hpf}$ and remained essentially stable at later times. This result may indicate, either that there is a unique period of time during which the PLL ganglion can be regenerated, or that regeneration takes place between 8 and $22 \mathrm{~h}$ after ablation, whenever ablation is done. To decide between these two possibilities, we examined the extent of regeneration after ablation at different times.

When ablation was performed at 25-27 hpf, a new ganglion was observed on the next day in 31 of 33 cases. The regenerated ganglion appears almost as large as in the control in 25 of the 31 cases (Fig. $6 \mathrm{H}$ ). That the ganglion was not completely normal, however, was revealed by the occasional formation of ectopic ventral nerves extending over the yolk (Fig. 6I) or by irregularities in ganglion shape (data not shown). When ablation was performed between 30 and $36 \mathrm{hpf}$, regeneration was still observed $2 \mathrm{~d}$ later in 16 of 20 cases, although the ganglion was notably smaller than normal in 12 of these 16 cases (Fig. $6 J$ ). When ablation is performed at 36-42 hpf, only three of eight embryos showed regeneration $2 \mathrm{~d}$ later, and, in all cases, this was limited to a few neurons (Fig. $6 \mathrm{~K}$ ). Furthermore, those few neurons occupy an ectopic ventral location (Fig. $6 M$ ), and in many cases, they do not establish a proper projection in the hindbrain (data not shown). It seems possible, therefore, that these neurons do not belong to the PLL system and may, at least in some cases, be derived from the vagal ganglion, which normally occupies a position just ventral to the PLL ganglion (Fig. $6 M$, compare with $L$, the control side of the same embryo). 
Table 2. Extent of regeneration after ablation at different stages

\begin{tabular}{lllllll}
\hline Stage (hpf) & reg3 & reg2 & reg1 & reg0 & Mean & $n$ \\
\hline $22-26$ & 6 & 2 & 4 & 2 & $1.9 \pm 1.2$ & 14 \\
$27-32$ & 0 & 7 & 5 & 2 & $1.4 \pm 0.7$ & 14 \\
$33-38$ & 0 & 0 & 6 & 4 & $0.6 \pm 0.5$ & 10
\end{tabular}

The stages were defined according to the position of the leading edge of the primordium on somites $3-10,11-20$, or 21-30, respectively (at this stage of embryonic development, the position of the PLL primordium is the best measure of developmental stage) (Kimmel et al., 1995). The number of cases showing extensive ganglion regeneration (reg3), substantial regeneration (reg2), limited regeneration (reg1), or no regeneration (reg0) $24 \mathrm{~h}$ after ablation are shown; see Materials and Methods for the criteria used. Means are based on the score (between 0 and 3) indicated for each ganglion.
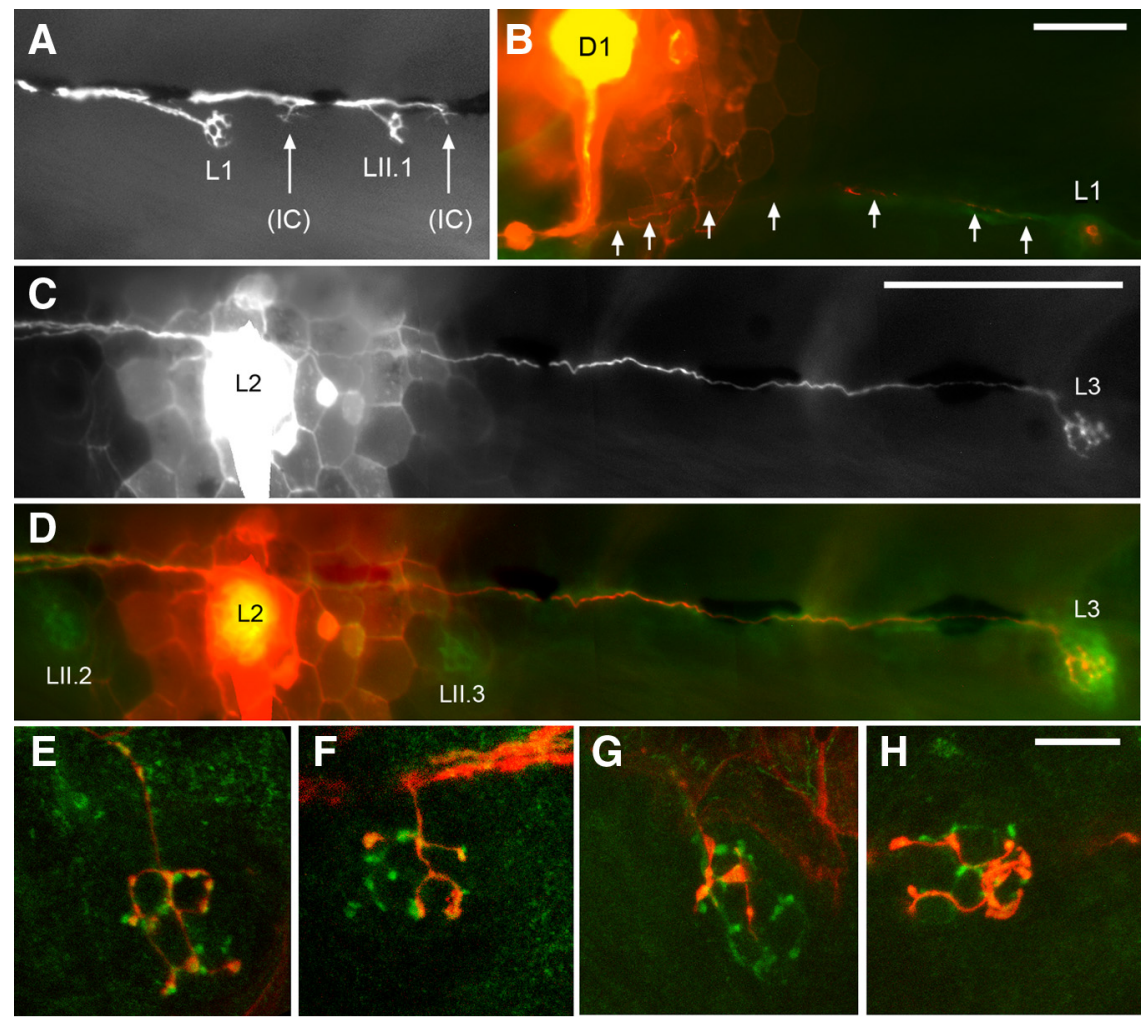

LII.3
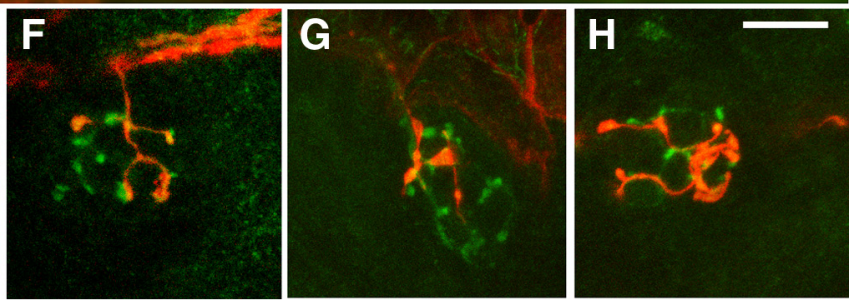

Figure 7. Specificity of innervation by PLL neurons. $A$, Dil labeling of the PLL nerve at $3 \mathrm{dpf}$, after ganglion ablation around 30 hpf, reveals innervation of $L I$ and LII neuromasts, as well as of incipient intercalary (IC) neuromasts. B, Dye injection in D1 reveals coinnervation with L1. Arrows indicate Dil-labeled fibers in the lateral PLL nerve. $C, D$, Dye injection in L2 reveals coinnervation with L3, but not with primll-derived LII.2 or LII.3.E, H, Dye injection in islet:gfp embryos distinguishes afferent (red) and efferent (green) branches. The injected neuromast was LII.2; afferent branches are observed in LII.1 (E), in L1 $(\boldsymbol{F})$, and occasionally in both LII.1 (G) and $\mathrm{L} 1(\boldsymbol{H})$ of the same embryo. Scale bars: $\boldsymbol{A}, \boldsymbol{B}, 100 \mu \mathrm{m} ; \boldsymbol{E}-\boldsymbol{H}, 20 \mu \mathrm{m}$.

To obtain a better estimate of the time at which the capability to regenerate declines, we staged the embryos by determining the position of the primordium at the time of ablation, and we evaluated the extent of regeneration on a scale from 0 (no regeneration) to 3 (normal-looking ganglion; see Materials and Methods). The results are shown in Table 2. The substantial decrease between the last two stages indicates that the capability to form new neurons after ablation of the ganglion declines sharply around $32 \mathrm{hpf}$.

This result is fully consistent with a role of secondary neurons in the reinnervation. The secondary placode is completely distinct from the cells of the primary system at $24 \mathrm{hpf}$ and would therefore be unaffected by laser ablation of the ganglion at this time. In contrast, cells in the neural region of the secondary placode have become incorporated in the PLL ganglion on the next day as showed by our photoconversion experiments (Fig. $4 \mathrm{H}, \mathrm{J}$ ) and will therefore be eliminated by ganglion ablation at $48 \mathrm{hpf}$. The decline in regeneration around $32 \mathrm{hpf}$ coincides with the time at which D0, the have been deleted. common primordium that forms primII and primD, can be detected at the anterior edge of somite 1 , suggesting that the secondary placode has delaminated and produced both a sensory primordium and sensory neurons at $32 \mathrm{hpf}$.

\section{Neuromast innervation by the regenerated ganglion}

Ganglion ablation at $24 \mathrm{hpf}$ results in a vast increase in the number of neuromasts at $4.5 \mathrm{dpf}$, because of the formation of precocious intercalary neuromasts by interneuromast cells. Interneuromast cells deposited by primI are normally kept quiescent for several days by the glial cells that accompany the afferent axons (Grant et al., 2005; Lopez-Schier and Hudspeth, 2005). Ganglion ablation prevents the migration of glial cells along afferent axons (Gilmour et al., 2002), therefore leading to precocious proliferation of interneuromast cells and to the formation of intercalary neuromasts. We examined the extent of reinnervation after ganglion ablation at $24 \mathrm{hpf}$ in seven SqET20 embryos, where the mantle cells of neuromasts and the interneuromast cells express GFP (Parinov et al., 2004). We scored the result in $4.5 \mathrm{dpf}$ larvae, a time when large numbers of precocious intercalary neuromasts have formed along the myoseptum of the ablated side. We used immunolabeling against GFP, to detect all neuromasts, and against acetylated tubulin, to detect all neurites.

The number of lateral neuromasts on the control side was $11.4 \pm 1.3$, all of which were innervated. On the ablated side, the number was $19.4 \pm 3.2$, of which $12.1 \pm 3.4$ were innervated. The uninnervated neuromasts were always the posteriormost of the fish (supplemental Fig. 1A, available at www. jneurosci.org as supplemental material). The terminal neuromasts, in particular, were never innervated (supplemental Fig. $1 B$, compare with $C$ on the control side, available at www.jneurosci.org as supplemental material). Anterior neuromasts were all innervated, suggesting that neurons derived from the secondary placode can innervate embryonic and intercalary neuromasts derived from primI- as well as primII-derived neuromasts.

We confirmed this conclusion by performing ganglion ablation at $24 \mathrm{hpf}$ in SqET20,Huc:kaede embryos and noting the position of the primary neuromasts at $48 \mathrm{hpf}$. We then examined the pattern of innervation at $4.5 \mathrm{dpf}$, after a brief exposure to UV light to convert Kaede to its red-fluorescing form. We observed that the regenerated ganglion innervates primary and intercalary as well as secondary neuromasts (supplemental Fig. $1 D-H$, available at www.jneurosci.org as supplemental material). Innervation of primary, secondary, and intercalary neuromasts can already be observed at $3 \mathrm{dpf}$ (Fig. 7A). We conclude that secondary neurons do not discriminate between primary and secondary neuromasts, at least in conditions in which the primary neurons

We assessed the specificity of regenerated ganglia by injecting DiI in individual neuromasts in SqET20 embryos. Based on nine 
Table 3. Specificity of neuromast innervation

\begin{tabular}{|c|c|c|c|c|c|c|c|c|c|c|c|c|}
\hline \multirow{2}{*}{$\begin{array}{l}\text { Injected } \\
\text { neuromast }\end{array}$} & \multirow[b]{2}{*}{$n$} & \multicolumn{3}{|c|}{ priml derived } & \multicolumn{2}{|c|}{ primll derived } & \multicolumn{3}{|c|}{ primD derived } & \multicolumn{3}{|c|}{ Specificity (\%) } \\
\hline & & L1 & $\mathrm{L} 2$ & L3 & LII.1 & LII.2 & D1 & $\mathrm{D} 2$ & D3 & NM & prim & no \\
\hline$L 2$ & 49 & 3 & 22 & 24 & 2 & 3 & 0 & 0 & 0 & 45 & 90 & 10 \\
\hline LIIO.2 & 36 & 3 & 2 & 0 & 4 & 28 & 0 & 0 & 0 & 77 & 86 & 14 \\
\hline$D 2$ & 15 & 1 & 0 & 0 & 0 & 0 & 1 & 11 & 2 & 73 & 94 & 6 \\
\hline
\end{tabular}

$n$, Total number of successful labelings for each neuromast. The number of cases in which neurons innervating the injected neuromast also innervated the neuromast is indicated at the top of the column. Bold italic numbers indicate the numbers of cases in which innervation was restricted to the Dil-injected neuromast. NM, The percentage of cases in which only the injected neuromast was innervated; prim, the percentage of cases in which only neuromasts derived from the same primordium were innervated; $n$, the percentage of cases in which neuromasts derived from another primordium were also innervated. This category includes the cases in which the injected neuromast was coinnervated with other neuromasts from the same and from another primordium.

injections (three in the primary neuromast L2, three in the secondary neuromast LII.2, and three in a precocious intercalary), we observed that the neurons that innervate a given neuromast innervate another $2 \pm 1.1$ neuromasts. In our small sample, all injected neurons were coinnervating at least one other neuromast. The coinnervated neuromasts were usually adjacent to the injected neuromast and never further than five somites away. Of 18 coinnervated neuromasts, 14 belonged to a category different from that of the injected neuromast (primary, secondary, or intercalary). Specifically, the three injections in LII.2 revealed coinnervation with four nearby neuromasts, two of which were primary and the other two intercalary, confirming a lack of specificity in the reinnervation process.

We observed that, regardless of the identity of the injected neuromast, the type distribution of coinnervated neuromasts closely reflects the type distribution of available neuromasts: the numbers of neuromasts localized within five somites of the nine injected neuromasts were 19 primary, 15 secondary, and 37 intercalary, of which coinnervation involved 4,3 , and 11 , respectively. This proportionality supports the idea that, in conditions in which the primary neurons have been depleted, secondary neurons display no preference toward neuromasts derived from their own placode.

\section{Placodal specificity of afferent neurons}

We examined whether the lack of specificity during reinnervation holds true in normal conditions as well. We first used cldnb:gfp embryos to evaluate the incidence of coinnervation of neuromasts from different lines. When DiI was injected in LI neuromasts, we found that neurons also innervate another primary neuromast in about half of the cases (Fig. $7 C, D$ ), as already documented by Nagiel et al. (2008), and rarely innervate a secondary neuromast. When DiI was injected in LII neuromasts, the proportion of larvae where neurons also innervate another neuromast was only one-fourth, but among the cases of coinnervation, one-half involves primary neuromasts.

Coinnervation of neuromasts generated by different primordia might reflect inadvertent labeling of efferent terminals. Neuromasts are innervated by efferent axons from neurons located in the midbrain and hindbrain (Metcalfe et al., 1985). Because the total number of efferent neurons is much smaller than the total number of neuromasts in all fish species studied to date, each efferent presumably innervates several neuromasts, and efferent neurons have been reported to supply both the ear and the PLL (Bell, 1981). To discriminate the two types of neurons with certainty, we used islet:gfp embryos, where the efferent neurons are labeled with GFP. In these embryos, GFP and DiI labeling can be distinguished using a spectral confocal microscope (Fig. 7E-H) (see Materials and Methods).

We observed that DiI injection at the level of the hair cell nuclei, as seen under Nomarski optics, rarely labels the efferent neurons ( $<10 \%$ of the cases of multiple neuromast innervation). This low frequency is surprising because the efferent terminals are often closely apposed to the afferents (Fig. 7E,F). As noted previously (Nagiel et al., 2008), the afferent terminals establish larger synaptic contacts with hair cells (Fig. $7 G, H$ ), possibly explaining why most injections specifically labeled the afferent neurons.

Using this method, we examined the specificity of afferent neurons that innervate representatives of the different classes of neuromasts: L2, derived from primI; LII.2, derived from primII; and $\mathrm{D} 2$, derived from primD. The results are presented in Table 3. The mean number of primary neuromasts sharing sensory neurites, as determined by DiI injection in L2, was 2.05, in excellent agreement with previous estimates based on single-neuron labeling (1.9-2.0) [Nagiel et al. (2008), their Fig. 3E]. Likewise, the proportion of primary neuromasts being singly innervated also agreed perfectly with previous data [22 of 49 (Table 3), 46 of 102 (Nagiel et al., 2008), and 45\% in both cases].

The results show that there is no strict specificity of innervation in the sense that a given afferent neuron can innervate several neuromasts derived from the same primordium, but also neuromasts derived from different primordia (Fig. $7 F, H$ ). We conclude, therefore, that neurons do not discriminate between neuromasts deposited by the various primordia, contrary to their complete discrimination of hair cell polarity within each neuromast (Nagiel et al., 2008; Faucherre et al., 2009). Despite this lack of specificity, the proportion of neurons that innervate exclusively neuromasts formed by a given primordium ranges from 85 to $95 \%$ (Table 3).

\section{Discussion}

The different steps in the formation of the zebrafish PLL system are summarized in Figure 8. Here we will examine three issues raised by our results: whether the primary and secondary placodes share a common origin; what is the relationship between 
the PLL system and other cranial placodes; and the specificity of afferent innervation.

The time course of retinoic acid requirement is closely superimposed for primI and primII/D neuromasts, and for their afferent neurons, arguing that the three types of PLL derivatives depend on a single retinoic acid-dependent event. The absence of correlation between the severity of primary and secondary defects in individual embryos makes it unlikely that the target of retinoic acid is another tissue that would later induce the various components of the PLL system. At the same time, the presence of embryos where the primary system is much more affected than the secondary system, or vice versa, suggests that fluctuations in the partitioning of a reduced field of precursor cells may favor either system at the expense of the other one, consistent with the idea that the different components of the PLL arise from a common pool of progenitors cells. More direct evidence will be needed to strengthen this conclusion, however.

If retinoic acid signaling is required for the formation of PLL progenitor cells between 8 and $10 \mathrm{hpf}$, one has to conclude that these cells have been set apart by $10 \mathrm{hpf}$. It has previously been noted that the progenitor cells of the primary primordium, primI, enter a phase of mitotic quiescence around $10 \mathrm{hpf}$ and do not resume proliferation until 16-18 hpf (Laguerre et al., 2005). These authors also noted that, whereas exposure to bromodeoxyuridine between 8 and $10 \mathrm{hpf}$ labels most PLL neurons, exposure starting at $10 \mathrm{hpf}$ labels only a few neurons, refining a previous finding that PLL neurons become postmitotic at some time between 8 and $13 \mathrm{hpf}$ (Metcalfe, 1983). Both results are consistent with the notion that PLL progenitor cells undergo a major transition leading to quiescence around $10 \mathrm{hpf}$, in agreement with our data indicating the existence of a crucial process between 8 and $10 \mathrm{hpf}$.

If the progenitor cells undergo a phase of transcriptional quiescence parallel to their mitotic quiescence, this would lead to a low concentration of Kaede protein. Since the secondary placode remains "dormant" much longer than the primary placode, this may explain why primary placode cells can be labeled by Kaede photoconversion at $17 \mathrm{hpf}$, whereas secondary cells can only be labeled at $20.5 \mathrm{hpf}$.

The second question we want to discuss is the relationship between the PLL system and other cranial placodes. The existence of a "pan-placodal field" from which all cranial placodes would originate has been comprehensively reviewed (Baker and Bronner-Fraser, 2001), and its relevance for amphibian PLL development has been authoritatively assessed by Schlosser (2002). Placodal markers such as $d l x$, eyal, or six 4 genes (Akimenko et al., 1994; Sahly et al., 1999; Kobayashi et al., 2000) are expressed in a horseshoe-shaped region that would correspond to this panplacodal field. Their expression starts around $10 \mathrm{hpf}$, suggesting that retinoic acid signaling is required for PLL development before the onset of pan-placodal gene expression.

It is possible that pan-placodal gene expression begins at earlier times than reported so far, or that application and removal of DEAB take several hours to be effective. Alternatively, it may be that the order between the acquisition of pan-placodal properties, and of modality-specific properties, is unimportant and that various placodes acquire their identity before or after panplacodal genes are expressed. This hypothesis may account for the difference in phenocritical periods for the inner ear and PLL system documented here, and for the evidence that the induction of PLL and otic placodes are separate (for review, see Baker and Bronner-Fraser, 2001), in contrast to the increasing evidence that the otic and epibranchial placodes arise from a larger group of precursor cells that, presumably, also forms the PLL system (Schlosser, 2006; Sun et al., 2007; Freter et al., 2008).

The formation of posterior placodes is a multistep process (Nechiporuk et al., 2007). If several of these steps act in parallel rather than hierarchically, their temporal order would be irrelevant. In this view, pan-placodal genes would provide territories that have acquired distinct identities with a set of common attributes, such as delamination, epithelial-mesenchymal transition, or neurogenesis (Schlosser, 2006). The seemingly obvious idea "generic first, specific later" may therefore be misleading (for review, see Brunet and Ghysen, 1999).

The common attributes to vertebrate placodes resemble the attributes of proneural domains in the insect ectoderm, and the latter could be considered tiny placodes, equivalence groups that will generate one or a few sense organs and sensory neurons of a given type. The similarity extends to the capability of the otic placode to regenerate a new otic vesicle after removal of the normal one (Waddington, 1937), a typical feature of equivalence groups also associated with proneural competence in insect neurogenesis (Doe and Goodman, 1985). The establishment of a pan-placodal field in the chordate lineage may have emerged as a device to provide a cluster of nearby regions with a common, ancient set of cell properties.

The third aspect of our work that needs discussion is the puzzling capability of a ganglion to reform within $24 \mathrm{~h}$ of complete ablation (or extirpation) (Grant et al., 2005). We have shown that this capability coincides with the formation of a new set of neurons from the secondary placode. The fact that massive regeneration is observed after ablation at $24 \mathrm{hpf}$, although little, if any, regeneration followed ablations done at $48 \mathrm{hpf}$, is fully consistent with a role of secondary neurons in this process. The secondary placode is completely distinct from the PLL ganglion at $24 \mathrm{hpf}$ (Fig. 3C-E) and would be unaffected by laser ablation of the ganglion at this time. In contrast, secondary neural cells have become incorporated in the ganglion at $48 \mathrm{hpf}$, as shown by our photoconversion experiments, and will therefore be eliminated by ganglion ablation at $48 \mathrm{hpf}$. We conclude that the regenerated ganglion is probably made of placode II-derived neurons that would have joined the PLL ganglion anyway, some time around $32 \mathrm{hpf}$, in the normal course of development.

All hair cells of primary neuromasts are polarized in the anteroposterior direction, whereas secondary neuromasts have dorsoventrally polarized hair cells (Lopez-Schier et al., 2004). Keeping separate the information from primary and secondary systems might therefore provide potentially useful information about the direction of water flow. We observed that some neurons innervate simultaneously LI and LII neuromasts (Fig. $7 F, H$ ), and even LI and D neuromasts (Fig. $7 B$ ). We also observed that, despite the absence of discrimination between primary and secondary neuromasts, there is a high level of specificity in the innervation, since only $10 \%$ of the afferent neurons coinnervate neuromasts deposited by different primordia (Table 3). The simplest interpretation of these results is that the specificity shown in the pattern of innervation is circumstantial and depends strictly on the temporal pattern of neuromast deposition.

Because LI neuromasts are deposited with a periodicity of a few hours, growing axons are presented with several maturing neuromasts at once and may establish functional synapses with consecutive neuromasts over the course of a few hours. LII and D neuromasts are deposited much more slowly, with a periodicity close to $1 \mathrm{~d}$ (Nuñez et al., 2009). Axons extended by developing secondary neurons will therefore have a more limited choice, and the specificity of those neurons will be higher (75\% of LII and D 
neuromasts are singly innervated, instead of $45 \%$ for the LI neuromasts). On the other hand, secondary neurons will also be presented with extant primary neuromasts and may occasionally succeed in stabilizing branches to them, explaining why secondary neurons innervate primary neuromasts more often than primary neurons do with secondary neuromasts.

If the ganglion is ablated at $24 \mathrm{hpf}$, the number of neuromasts coinnervated at $4.5 \mathrm{dpf}$ is $3.1 \pm 1.1$ neuromasts $(n=9)$, instead of $2.05 \pm 1.1$ for normal primary neurons $(n=49)$ and $1.3 \pm 0.5$ for normal secondary neurons $(n=36)$, reflecting the availability of more neuromasts. Reinnervation stopped before reaching the posteriormost neuromasts, but we do not know whether this reflects a limited capability of neurons to innervate more than three neuromasts simultaneously, or whether it reflects a slower progression of neurites toward the tip of the tail. Whatever the case, we observed that the choice of which neuromasts will be coinnervated reflects the distribution of the different types of neuromasts that are present nearby, indicating a complete lack of intrinsic specificity.

We conclude that a simple model in which newly grown neurons tend to innervate newly formed neuromasts first, and may occasionally extend branches into existing neuromasts, would produce the strongly biased pattern of innervation of Table 3, where the proportion of neurons that innervate exclusively neuromasts derived from the same primordium ranges from 85 to $95 \%$, effectively segregating the information derived from primary and secondary neuromasts, as well as from the dorsal and the lateral lines (Table 3). Whether or not the fish brain actually takes advantage of this segregation is not known.

\section{References}

Akimenko MA, Ekker M, Wegner J, Lin W, Westerfield M (1994) Combinatorial expression of three zebrafish genes related to distal-less: part of a homeobox gene code for the head. J Neurosci 14:3475-3486.

Andermann P, Ungos J, Raible D (2002) Neurogenin1 defines zebrafish cranial sensory ganglia precursors. Dev Biol 251:45-58.

Ando R, Hiroshi H, Yamamoto-Hino M, Mizuno H, Miyawaki A (2002) An optical marker based on the UV-induced green to-red photoconversion of a fluorescent protein. Proc Natl Acad Sci U S A 99:12651-12656.

Baker CV, Bronner-Fraser M (2001) Vertebrate cranial placodes I. Embryonic induction. Dev Biol 232:1-61.

Baker CV, O’Neill P, McCole RB (2008) Lateral line, otic and epibranchial placodes: developmental and evolutionary links? J Exp Zool B Mol Dev Evol 310:370-383.

Bell CC (1981) Central distribution of octavolateral afferents and efferents in a teleost (Mormyridae). J Comp Neurol 195:391-414.

Bessarab DA, Chong SW, Korzh V (2004) Expression of zebrafish six 1 during sensory organ development and myogenesis. Dev Dyn 230:781-786.

Brunet JF, Ghysen A (1999) Deconstructing cell determination: proneural genes and neuronal identity. Bioessays 121:313-318.

Coombs S, Görner P, Münz H (1989) The mechanosensory lateral line: neurobiology and evolution. New York: Springer.

Doe CQ, Goodman CS (1985) Early events in insect neurogenesis. II. The role of cell interactions and cell lineage in the determination of neuronal precursor cells. Dev Biol 111:206-219.

Durston AJ, Timmermans JPM, Hage WJ, Hendricks HFJ, de Vries NJ, Heideveld M, Nieuwkoop PD (1989) Retinoic acid causes an ateroposterior transformation in the developing nervous system. Nature 340: $140-144$.

Faucherre A, Pujol-Martí J, Kawakami K, López-Schier H (2009) Afferent neurons of the zebrafish lateral line are strict selectors of hair-cell orientation. PLoS One 4:e4477.

Freter S, Muta Y, Mak SS, Rinkwitz S, Ladher RK (2008) Progressive restriction of otic fate: the role of FGF and Wnt in resolving inner ear potential. Development 135:3415-3424.

Ghysen A, Dambly-Chaudière C (2007) The lateral line microcosmos. Genes Dev 21:2118-2130.

Gilmour DT, Maischein HM, Nusslein-Volhard C (2002) Migration and function of a glial subtype in the vertebrate peripheral nervous system. Neuron 34:577-588.

Gilmour D, Knaut H, Maischein HM, Nüsslein-Volhard C (2004) Towing of sensory axons by their migrating target cells in vivo. Nat Neurosci 7:491-492.

Grant KA, Raible DW, Piotrowski T (2005) Regulation of latent sensory hair cell precursors by glia in the zebrafish lateral line. Neuron 45:69-80.

Haas P, Gilmour D (2006) Chemokine signaling mediates self-organizing tissue migration in the zebrafish lateral line. Dev Cell 10:673-680.

Kimmel CB, Ballard WW, Kimmel SR, Ullmann B, Schilling TF (1995) Stages of embryonic development of the zebrafish. Dev Dyn 203:253-310.

Kobayashi M, Osanai H, Kawakami K, Yamamoto M (2000) Expression of three zebrafish Six4 genes in the cranial sensory placodes and the developing somites. Mech Dev 98:151-155.

Kopinke D, Sasine J, Swift J, Stephens WZ, Piotrowski T (2006) Retinoic acid is required for endodermal pouch morphogenesis and not for pharyngeal endoderm specification. Dev Dyn 235:2695-2709.

Laguerre L, Soubiran F, Ghysen A, König N, Dambly-Chaudière C (2005) Cell proliferation in the developing lateral line system of zebrafish embryos. Dev Dyn 233:466-472.

Lopez-Schier H, Hudspeth AJ (2005) Supernumerary neuromasts in the posterior lateral line of zebrafish lacking peripheral glia. Proc Natl Acad Sci U S A 102:1496-1501.

Lopez-Schier H, Starr CJ, Kappler JA, Kollmar R, Hudspeth AJ (2004) Directional cell migration establishes the axes of planar polarity in the posterior lateral-line organ of the zebrafish. Dev Cell 7:401-412.

Metcalfe WK (1983) Anatomy and development of the zebrafish posterior lateral line system. $\mathrm{PhD}$ thesis, University of Oregon.

Metcalfe WK (1985) Sensory neuron growth cones comigrate with posterior lateral line primordium cells in zebrafish. J Comp Neurol 238:218-224.

Metcalfe WK, Kimmel CB, Schabtach E (1985) Anatomy of the posterior lateral line system in young larvae of the zebrafish. J Comp Neurol 233:377-389.

Nagiel E, Andor-Ardo D, Hudspeth AJ (2008) Specificity of afferent synapses onto plane-polarized hair cells in the posterior lateral line of the zebrafish. J Neurosci 28:8442-8453.

Nechiporuk A, Linbo T, Poss KD, Raible DW (2007) Specification of epibranchial placodes in zebrafish. Development 134:611-623.

Nuñez VA, Sarrazin AF, Cubedo N, Allende ML, Dambly-Chaudière C, Ghysen A (2009) Post-embryonic development of the posterior lateral line in the zebrafish. Evol Dev 11:391-404.

Parinov S, Kondrichin I, Korzh V, Emelyanov A (2004) Tol2 transposonmediated enhancer trap to identify developmentally regulated zebrafish genes in vivo. Dev Dyn 231:449-459.

Ruiz i Altaba A, Jessell T (1991) Retinoic acid modifies mesodermal patterning in early Xenopus embryos. Genes Dev 5:175-187.

Sahly I, Andermann P, Petit C (1999) The zebrafish eyal gene and its expression pattern during embryogenesis. Dev Genes Evol 209:399-410.

Sapède D, Gompel N, Dambly-Chaudière C, Ghysen A (2002) Cell migration in the postembryonic development of the fish lateral line. Development 129:605-615.

Sato T, Takahoko M, Okamoto H (2006) HuC:Kaede, a useful tool to label neural morphologies in networks in vivo. Genesis 44:136-142.

Schlosser G (2002) Development and evolution of lateral line placodes in amphibians I. Development. Zoology (Jena) 105:119-146.

Schlosser G (2006) Induction and specification of cranial placodes. Dev Biol 294:303-351.

Stafford D, Prince VE (2002) Retinoic acid signaling is required for a crtitical early step in zebrafish pancreatic development. Curr Biol 12:1215-1220.

Sulston JE, White JG (1980) Regulation and cell autonomy during postembryonic development of Caenorhabditis elegans. Dev Biol 78:577-597.

Sun SK, Dee CT, Tripathi VB, Rengifo A, Hirst CS, Scotting PJ (2007) Epibranchial and otic placodes are induced by a common Fgf signal, but their subsequent development is independent. Dev Biol 303:675-686.

Villablanca EJ, Renucci A, Sapède D, Lec V, Soubiran F, Sandoval PC, Dambly-Chaudière C, Ghysen A, Allende M (2006) Control of cell migration in the zebrafish lateral line: implication of the gene "tumourassociated calcium signal transducer," tacstd. Dev Dyn 235:1578-1588.

Waddington $\mathrm{CH}$ (1937) The determination of the auditory placode in the chick. J Exp Zool 14:232-239.

Westerfield M (2000) The zebrafish book: guide for the laboratory use of zebrafish (Danio rerio). Eugene, OR: University of Oregon. 